\title{
Determination of energy intake and dietary habits and their relationship with physical activity levels and healthy lifestyle behaviours of primary education and pre-service teachers
}

Authors' Contribution: A Study Design B Data Collection C Statistical Analysis D Data Interpretation E Manuscript Preparation $\mathbf{F}$ Literature Search G Funds Collection

\author{
Arzu Özkan 1 ABCDEFG, Taner Bozkuş̧ ${ }^{2 ~ A B C D E F G}$, Ali Özkan³ CDEF, Gürhan Kayihan 4 CDEF \\ ${ }^{1}$ Alparslan Primary School, Ankara, Turkey \\ 2 Faculty of Sport Sciences, Bartın University, Bartın, Turkey \\ ${ }^{3}$ Faculty of Sport Science, Yozgat Bozok University, Yozgat, Turkey \\ ${ }^{4}$ Healthshare MSK Outpatient Physiotherapy Department, \\ Wallingford Community Hospital, Oxford Health NHS Trust, Oxford, UK, United Kingdom
}

\section{abstract}

Background: Participation in physical activity (PA) from a young age helps to build the foundation for a healthy life in the future. The purpose of this study was to investigate the relationships between energy intake, dietary habits, PA levels, and healthy lifestyle behaviours (HLSBs) in primary education and pre-service teachers.

Material and methods: A total of 105 primary education teachers (69 female, 36 male) and 95 pre-service teachers (64 female, 31 male) participated voluntarily in this study. To determine energy intake and dietary habits, participants completed a form detailing what they had consumed during the previous 24 hours. The short form of the International Physical Activity Questionnaire (IPAQ) was used to determine PA levels. HLSB scores were calculated using the Health-Promoting Lifestyle Profile questionnaire.

Results: There were significant differences in PA levels, HLSB scores and calcium intake between primary education and pre-service teachers $(p<0.05)$. Compared to pre-service teachers, PA levels were significantly lower in primary education teachers, whereas HLSB scores and calcium intake were significantly higher $(p<0.05)$. The correlation analysis indicated significant positive correlations between energy intake/dietary habits, PA levels, and HLSBs $(p<0.05)$.

Conclusions: This study suggests that HLSBs are indicators of PA levels and energy intake/dietary habits in primary education and pre-service teachers.

Key words: exercise, health promotion, nutrition, school teacher, sedentary lifestyle, student teacher.

\section{article details}

Article statistics: Word count: 3,410; Tables: 6; Figures: 0; References: 30

Received: April 2021; Accepted: August 2021; Published: December 2021

Full-text PDF: http://www.balticsportscience.com

Copyright @ Gdansk University of Physical Education and Sport, Poland

Indexation: Celdes, Clarivate Analytics Emerging Sources Citation Index (ESCI), CNKI Scholar (China National Knowledge Infrastructure), CNPIEC, DOAJ, EBSCO - Central \& Eastern European Academic Source, EBSCO - SPORTDiscus, EBSCO Discovery Service, Google Scholar, Index Copernicus, J-Gate, Naviga (Softweco, Primo Central (ExLibris), ProQuest - Family Health, ProQuest - Health \& Medical Complete, ProQuest - Illustrata: Health Sciences, ProQuest Nursing \& Allied Health Source, Summon (Serials Solutions/ProQuest, TDOne (TDNet), Ulrich's Periodicals Directory/ ulrichsweb, WorldCat (OCLC)

Funding: This research received no specific grant from any funding agency in the public, commercial, or not-for-profit sectors.

Conflict of interests: Corresponding author:

Open Access License: Authors have declared that no competing interest exists.

Dr. Gürhan KAYIHAN; Oxford Health NHS Trust, Wallingford Community Hospital, Healthshare MSK Outpatient Physiotherapy Department, Oxford, UK, United Kingdom, Wallingford, Oxfordshire, OX10 9DU, UK; e-mail: gkayihan@yahoo.com

This is an open access article distributed under the terms of the Creative Commons Attribution-Non-Commercial-NoDerivatives 4.0 International (https://creativecommons.org/licenses/by-nc-nd/4.0/), which permits use, distribution, and reproduction in any medium, provided the original work is properly cited, the use is non-commercial and is otherwise in compliance with the license. 


\section{INTRODUCTION}

Nowadays, people tend to lead sedentary lives, a behaviour associated with the increased development of technology. A sedentary lifestyle is closely associated with many diseases, such as coronary heart disease, high blood pressure, high blood lipid levels, type II diabetes, obesity, some cancers (e.g. colon and breast cancers) and musculoskeletal diseases, such as back pain [1, 2]. Studies show that regular physical activity (PA) and exercise are beneficial and play an important role in improving lipoprotein profiles, insulin sensitivity, levels of C-reactive protein, and coronary biomarkers, regulating blood pressure, and controlling weight [1]. In addition, regular PA and exercise play an important role in regulating depression and psychological features, such as anxiety levels. It is well known that regular PA prevents or retards chronic diseases [1,3]. Furthermore, PA and exercise develop individuals' physical fitness, thereby supporting a healthy lifestyle.

Taking care of one's health is an important factor in leading a healthy life. This includes being a non-smoker, abstaining from alcohol and drugs, maintaining healthy dietary habits, taking part in regular PA and exercise, keeping away from violence, having a healthy sex life, controlling weight, having healthy communication within the family and managing stress [4]. An individual who turns such behaviours into attitudes can sustain being healthy, and even improve their health. While healthy behaviour is considered to be all the actions that the individual adopts to stay healthy and to keep away from illness, a healthy lifestyle is defined to be one in which the individual controls all of the actions affecting their health [5]. If individuals want to have a healthy future or if they aim to increase the quality of their lives, they must adapt these behaviours to fit their lives. Therefore, having PA habits from childhood, making exercise an essential part of one's life or at least increasing the amount of daily PA are all important factors to maintain one's health and decrease the risk of illness that individuals may face in the future [6].

Increasing people's awareness of their PA levels, their dietary habits and energy intake resulting in them becoming more active will improve their quality of life and make them healthier. If PA habits are established in people's lives during their school years, then this will build a foundation for a healthy life in their future. From this perspective, if young adults know about the aspects of a healthy lifestyle and PA and if they apply these factors, this will provide them with advantages in their quality of life as adults [7]. This study has been designed within this context so that primary education and pre-service teachers will exhibit healthy behaviours and be good role models for their students, ensuring that society grows old healthily. The role of the primary education teacher is important in this respect because students, who are in their childhood, usually consider their teacher as a role model. Students that perceive a healthy lifestyle and apply it in their daily lives will have an advantage to have a healthy life. The objective of this study is to determine energy intake and dietary habits and investigate their association with healthy lifestyle behaviours (HLSB) and PA levels of primary education and pre-service teachers.

\section{MATERIALS AND METHODS}

\section{SUBJECTS AND EXPERIMENTAL APPROACH}

A total of 105 primary education teachers (69 female, 36 male) and 95 pre-service teachers (64 female, 31 male) from Bartın University, Faculty of Education, Fundamental Education Department and Elementary School Teaching voluntarily participated in this study.

\section{Health-Promoting Lifestyle Profile Scale}

The participants were asked to provide information about demographic factors, such as age, gender, and education. The Health-Promoting Lifestyle Profile Scale was used for collecting 
data on their health behaviours. The scale was developed by Walker et al. [8]. It is composed of 52 items and 6 subscales and consists of questions about health-promoting behaviours. The subscales covered self-actualization (SA), health responsibility (HR), exercise (E), nutrition $(\mathrm{N})$, interpersonal support (IS), and stress management (SM). The total score reflects the level of HLSB. Each respondent was asked to rate each item on a 1 to 4 response scale where 1, corresponds to never, 2 - sometimes, 3 - often and 4 - regularly.

The alpha coefficient of reliability for the scale was 0.92 ; the alpha coefficient of reliability for the subscales varied from 0.70 to 0.90 . The reliability of the scale for the Turkish population was tested, and the alpha coefficient of reliability was 0.91 in Esin's study [5].

\section{International Physical Activity Questionnaire (IPAQ)}

The short version of The International Physical Activity Questionnaire (IPAQ) was used to assess PA levels which were then scored according to the method of Craig et al. [18]. The questionnaire was devised to be used by individuals aged between 18 and 65 years. The questionnaire (9 items) gives information on the time spent walking, doing vigorous-intensity activity (VIA) to moderate-intensity activity (MIA) and inactivity. Data from the short IPAQ questionnaires were categorised according to the physical activities re $\neg$ corded (walking, MIA, and VIA). The total weekly PA was estimated by weighting the reported minutes per week within each activity category according to the metabolic equivalent of task (MET). The estimate of energy expenditure assigned to each category of activity is shown below:

- Walking MET-min/week $=3.3 \times$ walking time $(\min ) \times$ walking days $(1)$

- Moderate MET-min/week $=4 \times$ MIA time $(\min ) \times(2)$ moderate days

- Vigorous MET-min/week $=8 \times$ VIA time $(\min ) \times(3)$ vigorous days

- Total PA MET-min/week = sum of walking + moderate + vigorous (4)

The participants were classified as 'moderate' if they met at least one of the criteria below:

- 3 or more days of VIA of at least $20 \mathrm{~min} /$ day,

- 5 or more days of MIA and/or walking of at least $30 \mathrm{~min} /$ day,

- 5 or more days of any combination of walking, MIA or VIA achieving a minimum total PA of at least 600 MET-min/week.

The participants were classified as 'high' if they met at least one of the criteria below:

- VIA on at least 3 days achiev $\neg$ ing a minimum total PA of at least 1500 MET-min/week,

- 7 or more days of any combination of walking, MIA or VIA achieving a minimum total PA of at least 3000 MET-min/week.

Participants were considered to have a 'low' PA level if they did not meet criteria for moderate or high categories. In this study, PA levels of the participants were evaluated through the Turkish short version of IPAQ. The translation and validation study of the Turkish version of IPAQ indicated evidence for construct validity, criterion validity $(r=0.30)$, and test-retest stability $(r=0.69)$ [9].

\section{Intake of Energy and Nutrients (Dietary Habits)}

The 24-hour food consumption method was employed in this study, as it is a frequently used method. Individuals were asked to complete a form about what they had eaten and drunk within the last 24 hours. This was repeated for three successive days (two days during the working week, one day during the weekend). Measuring was performed using the dish (portion) models of foods and home dimensions: water glass, tea glass, coffee cup, cup, soup spoon (topful), scoop, sweet spoon, small, medium size, large size, etc. The amounts of energy and nutrients provided by each food were calculated using nutrient composition tables. The total amounts of energy and nutrients from all days were divided by the total number of days, and the amount of mean daily food types and nutrients were found. Energy and nutrient intakes were estimated using Bebis 7.2 software. 


\section{STATISTICAL ANALYSES}

For all data, the descriptive statistics (mean and standard deviation) were applied. The relationship between energy and nutrient intakes (dietary habits) and PA levels were determined with the Pearson Multiplication Moments Correlation Analysis.

\section{RESULTS}

The mean and standard deviation values of anthropometric characteristics for the primary education and pre-service teachers are given in Table 1. There are significant differences in age, body weight, body height and BMI between female pre-service teachers and male preservice teachers and in body weight, body height and BMI between female primary education teachers and male primary education teachers $(p<0.05)$. The BMI of the primary education teachers was found to be $24.47 \pm 5.23 \mathrm{~kg} / \mathrm{m}^{2}$; the BMI of the male primary education teachers was found to be $27.64 \pm 3.45 \mathrm{~kg} / \mathrm{m}^{2}$ and the BMI of the female primary education teachers was found to be $22.81 \pm 5.25 \mathrm{~kg} / \mathrm{m}^{2}$. Concerning the pre-service teachers, the BMI was found to be 23.20 \pm 3.83 ; the BMI of the female pre-service teachers was $21.97 \pm 3.71 \mathrm{~kg} / \mathrm{m}^{2}$, while the BMI of the male pre-service teachers was $25.72 \pm 2.69 \mathrm{~kg} / \mathrm{m}^{2}$.

Table 1. Mean and standard deviation values of the body composition of the primary education teachers and pre-service teachers

\begin{tabular}{lcccc} 
& Age (years) & Body weight $(\mathrm{kg})$ & Height $(\mathrm{cm})$ & BMI $\left(\mathrm{kg} / \mathrm{m}^{2}\right)$ \\
\hline $\begin{array}{l}\text { Primary education teachers and } \\
\text { pre-service teachers }(\mathrm{n}=200)\end{array}$ & $32.31 \pm 13.24$ & $66.78 \pm 17.10$ & $166.44 \pm 8.84$ & $23.86 \pm 4.65$ \\
$\begin{array}{l}\text { Primary education teachers } \\
(\mathrm{n}=105)\end{array}$ & $43.15 \pm 9.21$ & $67.77 \pm 16.90$ & $165.66 \pm 7.11$ & $24.47 \pm 5.23$ \\
$\begin{array}{l}\text { Female primary education } \\
\text { teachers ( } \mathrm{n}=69)\end{array}$ & $40.37 \pm 8.49^{\mathrm{a}}$ & $60.23 \pm 14.02^{\mathrm{a}}$ & $162.44 \pm 5.13^{\mathrm{a}}$ & $22.81 \pm 5.25^{\mathrm{a}}$ \\
$\begin{array}{l}\text { Male primary education teachers } \\
(\mathrm{n}=36)\end{array}$ & $48.47 \pm 8.24^{\mathrm{a}}$ & $82.22 \pm 11.83^{\mathrm{a}}$ & $172.42 \pm 5.27^{\mathrm{a}}$ & $27.64 \pm 3.45^{\mathrm{a}}$ \\
$\begin{array}{l}\text { Pre-service teachers ( } \mathrm{n}=95) \\
\begin{array}{l}\text { Female pre-service teachers } \\
(\mathrm{n}=64)\end{array}\end{array}$ & $20.32 \pm 1.05$ & $65.69 \pm 17.35$ & $167.29 \pm 10.40$ & $23.20 \pm 3.83$ \\
$\begin{array}{l}\text { Male pre-service teachers } \\
(\mathrm{n}=31)\end{array}$ & $20.29 \pm 1.01$ & $57.45 \pm 10.37^{\mathrm{b}}$ & $161.91 \pm 6.06^{\mathrm{b}}$ & $21.97 \pm 3.71^{\mathrm{b}}$ \\
\hline
\end{tabular}

BMI - Body mass index; kg - kilogram; cm - centimetre; $\mathrm{m}^{2}$ - square metre; ${ }^{\mathrm{a}}$ - significant difference between female and male primary education teachers; ${ }^{b}$ - significant difference between female and male pre-service teachers, $p<0.05$

Table 2 shows the mean and standard deviation of the PA levels of the elementary school teachers and the elementary pre-service teachers. The PA level of the pre-service teachers was 1847.19 , which was significantly $(\mathrm{p}<0.05)$ higher than the PA level of the primary school teachers (1650.31). In both groups, the levels of total PA and vigorous-intensity activity were higher in males.

Table 3 shows the HLSB scores of female and male pre-service teachers. There were significant differences $(\mathrm{p}<0.05)$ in $\mathrm{HR}, \mathrm{E}$ and HLSB between pre-service and primary education teachers. While the mean HLSB score of the pre-service teachers was found to be 122, the mean HLSB score of the primary education teachers was found to be 139, which is 17 points higher. There were significant differences $(\mathrm{p}<0.05)$ in $\mathrm{N}$ and HLSB between female pre-service teachers and female primary education teachers. Significant differences $(\mathrm{p}<0.05)$ were also found in N and HLSB between male pre-service teachers and male primary education teachers. 
Table 2. Mean and standard deviation values of physical activity levels of the primary education teachers and pre-service teachers

\begin{tabular}{lcccccc} 
& $\begin{array}{c}\text { PET } \\
(\mathrm{n}=105)\end{array}$ & $\begin{array}{c}\text { Female PET } \\
(\mathrm{n}=69)\end{array}$ & $\begin{array}{c}\text { Male PET } \\
(\mathrm{n}=36)\end{array}$ & $\begin{array}{c}\text { PST } \\
(\mathrm{n}=95)\end{array}$ & $\begin{array}{c}\text { Female PST } \\
(\mathrm{n}=64)\end{array}$ & $\begin{array}{c}\text { Male PST } \\
(\mathrm{n}=31)\end{array}$ \\
\hline $\begin{array}{l}\text { Walking } \\
\text { (3.3 MET) }\end{array}$ & 1015.45 & 1154.25 & 780.57 & 1166.55 & 1306.20 & 1255.40 \\
$\begin{array}{l}\text { Moderate-intensity activity } \\
\text { (4.0 MET) }\end{array}$ & $217.71^{\mathrm{a}}$ & 463.63 & 507.69 & $462.40^{\mathrm{a}}$ & 373.30 & 218.24 \\
$\begin{array}{l}\text { Vigorous-intensity activity } \\
\text { (8.0 MET) }\end{array}$ & $417.14^{\mathrm{a}}$ & $207.27^{\mathrm{c}}$ & $772.30^{\mathrm{c}}$ & $218.24^{\mathrm{a}}$ & $259.80^{\mathrm{b}}$ & $930.00^{\mathrm{b}}$ \\
\begin{tabular}{l} 
TOTAL \\
\hline
\end{tabular} & $1650.31^{\mathrm{a}}$ & $1407.88^{\mathrm{c}}$ & $2060.57^{\mathrm{c}}$ & $1847.19^{\mathrm{a}}$ & $1939.30^{\mathrm{b}}$ & $2403.64^{\mathrm{b}}$ \\
\hline
\end{tabular}

PET - primary education teacher; PST - pre-service teacher; ${ }^{a}$ - significant difference between PET and PST; ${ }^{b}$ - significant difference between PET female and PST female; ${ }^{c}$ - significant difference between PET male and PST male, $p<0.05$

Table 3. Mean and standard deviation values of healthy lifestyle behaviour scores of the primary education teachers and pre-service teachers

\begin{tabular}{lcccccc}
\hline & $\begin{array}{c}\text { PET } \\
(\mathrm{n}=105)\end{array}$ & $\begin{array}{c}\text { Female PET } \\
(\mathrm{n}=69)\end{array}$ & $\begin{array}{c}\text { Male PET } \\
(\mathrm{n}=36)\end{array}$ & $\begin{array}{c}\text { PST } \\
(\mathrm{n}=95)\end{array}$ & $\begin{array}{c}\text { Female PST } \\
(\mathrm{n}=64)\end{array}$ & $\begin{array}{c}\text { Male PST } \\
(\mathrm{n}=31)\end{array}$ \\
\hline Self-actualisation & 40.64 & 39.25 & 42.44 & 36.43 & 36.72 & 36.30 \\
(SA) & \pm 7.80 & \pm 8.46 & \pm 6.23 & \pm 6.06 & \pm 5.89 & \pm 6.56 \\
Health responsibility & 26.12 & 26.02 & 25.35 & 20.83 & 21.27 & 21.07 \\
(HR) & $\pm 6.88^{\mathrm{a}}$ & \pm 6.54 & \pm 7.52 & $\pm 6.44^{\mathrm{a}}$ & \pm 6.57 & \pm 6.38 \\
Exercise & 11.12 & 10.79 & 11.25 & 10.39 & 10.55 & 10.92 \\
(E) & $\pm 4.13 \mathrm{a}$ & \pm 3.70 & \pm 4.78 & $\pm 4.39^{\mathrm{a}}$ & \pm 4.68 & \pm 3.66 \\
Nutrition & 19.45 & 19.27 & 19.03 & 15.68 & 15.92 & 15.76 \\
(N) & \pm 2.89 & $\pm 2.92^{\mathrm{b}}$ & $\pm 2.86^{\mathrm{c}}$ & \pm 2.81 & $\pm 2.86 \mathrm{~b}$ & $\pm 3.03^{\mathrm{c}}$ \\
Interpersonal support & 21.78 & 21.09 & 22.10 & 20.20 & 20.07 & 20.07 \\
(IS) & \pm 3.62 & \pm 3.63 & \pm 3.38 & \pm 3.52 & \pm 3.42 & \pm 3.81 \\
Stress management & 19.80 & 19.81 & 19.07 & 18.41 & 18.47 & 18.30 \\
(SM) & \pm 4.90 & \pm 4.97 & \pm 4.90 & \pm 8.73 & \pm 9.42 & \pm 3.90 \\
Healthy lifestyle behaviour & 139.25 & 137.11 & 137.64 & 122.50 & 122.55 & 122.46 \\
(HLSB) total score & $\pm 24.20^{\mathrm{a}}$ & $\pm 23.71^{\mathrm{b}}$ & $\pm 25.02^{\mathrm{c}}$ & $\pm 20.18^{\mathrm{a}}$ & $\pm 19.96^{\mathrm{b}}$ & $\pm 22.44^{\mathrm{c}}$ \\
\hline
\end{tabular}

PET - primary education teacher; PST - pre-service teacher; ${ }^{a}$ - significant difference between PET and PST; ${ }^{b}$ - significant difference between PET female and PST female; ${ }^{c}$ - significant difference between PET male and PST male, $p<0.05$

The Pearson correlation analysis of HLSB scores and PA levels of the primary education and pre-service teachers were shown in Table 4 . There was a significant relationship between the exercise subscale behaviour score of HLSB and PA levels $(p<0.05)$.

Table 4. Determination of the relationship between healthy lifestyle behaviours and physical activity levels

\begin{tabular}{ccccccccc}
\hline & PA & SM & HLSB & E & N & SA & HR & IS \\
\hline SM & NS & - & $0.868^{* *}$ & $0.539^{* *}$ & $0.681^{* *}$ & $0.694^{*}$ & $0.701^{* *}$ & $0.516^{* *}$ \\
HLSB & NS & $0.868^{* *}$ & - & $0.675^{* *}$ & $0.807^{* *}$ & $0.796^{* *}$ & $0.890^{* *}$ & $0.704^{* *}$ \\
E & $0.201^{*}$ & $0.539^{* *}$ & $0.675^{* *}$ & - & $0.402^{* *}$ & $0.430^{* *}$ & $0.586^{* *}$ & $0.346^{* *}$ \\
N & NS & $0.681^{* *}$ & $0.807^{* *}$ & $0.402^{* *}$ & - & $0.605^{* *}$ & $0.709^{* *}$ & $0.486^{* *}$ \\
SA & NS & $0.694^{*}$ & $0.796^{* *}$ & $0.430^{* *}$ & $0.605^{* *}$ & - & $0.587^{* *}$ & $0.601^{* *}$ \\
HR & NS & $0.701^{* *}$ & $0.890^{* *}$ & $0.586^{* *}$ & $0.709^{* *}$ & $0.587^{* *}$ & - & $0.515^{* *}$ \\
IS & NS & $0.516^{* *}$ & $0.704^{* *}$ & $0.346^{* *}$ & $0.486^{* *}$ & $0.601^{* *}$ & $0.515^{* *}$ & - \\
BMI & NS & NS & NS & NS & NS & NS & NS & NS \\
\hline
\end{tabular}

SM - stress management; HLSB - healthy lifestyle behaviour; E - exercise; N - nutrition; SA - self-actualisation; HR health responsibility; IS - interpersonal support; BMI - body mass index; PA - physical activity, $p<0.05$ 
Table 5. Determination of the relationship between energy and nutrient intake, healthy lifestyle behaviours and physical activity levels of the primary education teachers and pre-service teachers

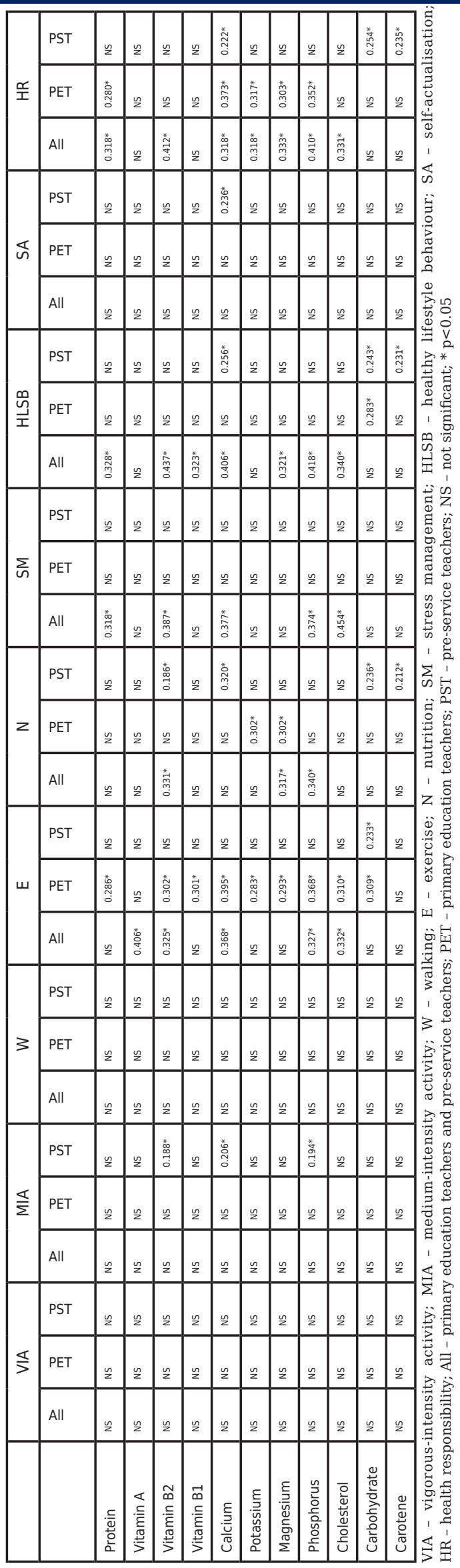


The Pearson correlation analysis of energy and nutrient intakes and HLSB scores and PA levels of the primary education teachers and pre-service teachers are shown in Table 5. There were significant relationships between energy and nutrient intakes, HLSB and PA levels (Protein-E, Protein-SM, Protein-HLSB, Protein-HR, Vitamin A-E, Vitamin B2-MIA, Vitamin B2-E, Vitamin B2-N, Vitamin B2-SM, Vitamin B2-HLSB, Vitamin B2-HR, Vitamin B1-E, Vitamin B1-HLSB, Calcium-MIA, Calcium-E, Calcium-N, Calcium-SM, Calcium-HLSB, Calcium-HR, Potassium-E, Potassium-N, Potassium-HR, Magnesium-E, Magnesium-N, Magnesium-HLSB, Magnesium-HR, Phosphorus-MIA, Phosphorus-E, Phosphorus-N, Phosphorus-SM, Phosphorus-HLSB, Phosphorus-HR, Cholesterol-E, Cholesterol-SM, Cholesterol-HLSB, Cholesterol-HR, Carbohydrate-E, Carbohydrate-N, Carbohydrate-HLSB, Carbohydrate-HR, Carotene-N, Carotene-HLSB, Carotene-HR) $(\mathrm{p}<0.05)$.

Table 6 shows the mean and standard deviation values of energy and nutrient intake of the primary education and pre-service teachers. There was a significant difference in calcium intake between primary education and pre-service teachers $(\mathrm{p}<0.05)$.

Table 6. Mean and standard deviation values of energy and nutrient intake of the primary education teachers and pre-service teachers

\begin{tabular}{|c|c|c|c|c|c|c|}
\hline & $\begin{array}{c}\text { PET } \\
(n=105)\end{array}$ & $\begin{array}{c}\text { Female PET } \\
(n=69)\end{array}$ & $\begin{array}{l}\text { Male PET } \\
(n=36)\end{array}$ & $\begin{array}{c}\text { PST } \\
(n=95)\end{array}$ & $\begin{array}{c}\text { Female PST } \\
(n=64)\end{array}$ & $\begin{array}{l}\text { Male PST } \\
(n=31)\end{array}$ \\
\hline Energy (kcal) & $1557.05 \pm 667.99$ & $1619.77 \pm 453.42^{\mathrm{a}}$ & $1480.19 \pm 269.48$ & $1568.70 \pm 411.90$ & $1609.47 \pm 461.38$ & $1484.59 \pm 271.65$ \\
\hline Water (g) & $1166.06 \pm 572.96$ & $1205.23 \pm 542.29$ & $1090.08 \pm 628.70$ & $968.25 \pm 518.80$ & $1071.07 \pm 505.53$ & $755.95 \pm 355.16$ \\
\hline Carbohydrate (g) & $143.95 \pm 75.08$ & $139.64 \pm 67.43$ & $152.20 \pm 88.33$ & $150.13 \pm 50.21$ & $152.57 \pm 57.75$ & $1450.08 \pm 29.28$ \\
\hline Carbohydrate (\%) & $33.93 \pm 12.86$ & $35.57 \pm 10.85$ & $30.80 \pm 15.69$ & $38.87 \pm 7.08$ & $38.18 \pm 6.97$ & $40.29 \pm 7.19$ \\
\hline Protein (g) & $60.37 \pm 25.84$ & $58.17 \pm 20.78$ & $64.60 \pm 33.42$ & $58.11 \pm 21.92$ & $56.79 \pm 20.70$ & $60.85 \pm 24.39$ \\
\hline Protein (\%) & $14.76 \pm 5.37$ & $15.55 \pm 4.63$ & $13.27 \pm 6.34$ & $15.10 \pm 3.87$ & $14.48 \pm 2.95$ & $16.38 \pm 5.10$ \\
\hline Fat (g) & $80.53 \pm 34.71$ & $77.89 \pm 29.84$ & $85.60 \pm 42.54$ & $80.75 \pm 22.32$ & $84.65 \pm 24.08$ & $72.69 \pm 15.59$ \\
\hline Fat (\%) & $42.47 \pm 14.53$ & $44.48 \pm 11.47$ & $38.66 \pm 18.63$ & $46.00 \pm 6.00$ & $47.29 \pm 6.02$ & $43.32 \pm 5.08$ \\
\hline Fibre (g) & $15.86 \pm 7.74$ & $16.12 \pm 7.30$ & $15.36 \pm 8.61$ & $14.52 \pm 4.59$ & $15.52 \pm 4.99$ & $12.44 \pm 2.69$ \\
\hline $\begin{array}{l}\text { Polyunsaturated } \\
\text { fatty acids (g) }\end{array}$ & $20.75 \pm 9.80$ & $20.56 \pm 8.93$ & $21.13 \pm 11.42$ & $24.08 \pm 8.30$ & $24.69 \pm 9.05$ & $22.81 \pm 6.44$ \\
\hline Vitamin A $(\mu \mathrm{g})$ & $1040.13 \pm 836.20$ & $1005.40 \pm 433.20$ & $1106.73 \pm 1306.22$ & $1331.80 \pm 2129.40$ & $770.44 \pm 225.93$ & $2490.70 \pm 3470.05$ \\
\hline Vitamin E ( $\mu \mathrm{g})$ & $20.27 \pm 9.34$ & $20.44 \pm 8.53$ & $19.94 \pm 10.83$ & $21.44 \pm 6.14$ & $22.61 \pm 6.25$ & $19.02 \pm 5.19$ \\
\hline Cholesterol (mg) & $262.06 \pm 133.30$ & $260.17 \pm 114.54$ & $265.67 \pm 165.21$ & $336.39 \pm 257.61$ & $281.15 \pm 141.99$ & $450.44 \pm 381.63$ \\
\hline Carotene (mg) & $2.57 \pm 1.69$ & $2.79 \pm 1.56$ & $2.14 \pm 1.87$ & $1.71 \pm 0.75$ & $1.98 \pm 0.72$ & $1.15 \pm 0.44$ \\
\hline Vitamin B1 (mg) & $0.60 \pm 0.29$ & $0.60 \pm 0.25$ & $0.61 \pm 0.36$ & $0.58 \pm 0.20$ & $0.58 \pm 0.18$ & $0.58 \pm 025$ \\
\hline Vitamin B2 (mg) & $1.18 \pm 0.55$ & $1.14 \pm 0.44$ & $1.26 \pm 0.71$ & $1.04 \pm 0.57$ & $0.94 \pm 0.27$ & $1.24 \pm 0.89$ \\
\hline Vitamin B6 (mg) & $0.96 \pm 0.42$ & $0.96 \pm 0.38$ & $0.95 \pm 0.49$ & $1.10 \pm 0.46$ & $1.05 \pm 0.39$ & $1.21 \pm 0.56$ \\
\hline Folic acid $(\mu \mathrm{g})$ & $213.34 \pm 96.13$ & $211.65 \pm 80.73$ & $216.59 \pm 121.57$ & $223.93 \pm 91.91$ & $218.16 \pm 55.98$ & $235.84 \pm 140.26$ \\
\hline Vitamin C (mg) & $81.36 \pm 49.47$ & $87.92 \pm 45.87$ & $68.78 \pm 54.19$ & $65.39 \pm 28.11$ & $73.86 \pm 27.63$ & $47.91 \pm 20.11$ \\
\hline Sodium (mg) & $3692.90 \pm 1676.99$ & $3491.73 \pm 1374.85$ & $4078.78 \pm 2109.79$ & $3652.25 \pm 950.55$ & $3888.25 \pm 977.17$ & $3164.79 \pm 679.42$ \\
\hline Potassium (mg) & $1842.20 \pm 837.98$ & $1862.23 \pm 745.42$ & $1804.03 \pm 1002.35$ & $1726.53 \pm 593.43$ & $1788.73 \pm 578.44$ & $1597.89 \pm 612.72$ \\
\hline Calcium (mg)* & $639.86 \pm 309.69 a$ & $638.21 \pm 264.71$ & $643.01 \pm 385.78$ & $454.75 \pm 159.12 a$ & $476.59 \pm 165.61$ & $409.69 \pm 136.44$ \\
\hline Magnesium (mg) & $210.82 \pm 94.75$ & $212.83 \pm 88.24$ & $206.98 \pm 107.35$ & $199.27 \pm 68.71$ & $210.83 \pm 68.29$ & $175.41 \pm 64.25$ \\
\hline Phosphorus (mg) & $927.07 \pm 400.24$ & $910.34 \pm 333.66$ & $959.14 \pm 508.72$ & $866.60 \pm 293.97$ & $856.40 \pm 276.08$ & $887.65 \pm 331.72$ \\
\hline Ferrous (mg) & $8.86 \pm 3.68$ & $8.77 \pm 3.28$ & $9.03 \pm 4.38$ & $8.85 \pm 3.31$ & $8.96 \pm 2.83$ & $8.62 \pm 4.17$ \\
\hline Zinc (mg) & $9.04 \pm 3.86$ & $8.61 \pm 3.03$ & $9.88 \pm 5.03$ & $8.13 \pm 2.77$ & $8.50 \pm 2.71$ & $7.37 \pm 2.78$ \\
\hline
\end{tabular}

kcal - kilocalorie; g - gram; $\mu \mathrm{g}$ - microgram; mg - milligram; PET - primary education teachers; PST - pre-service teachers; $*$ - p<0.05; - significant difference between PET and PST

\section{DISCUSSION}

In concordance with previous research on healthy lifestyles, dietary habits and PA, we discuss whether there is a relationship between energy and nutrient intakes (dietary habits), HLSB and PA levels in primary education and pre-service teachers, and evaluate the relationship 
between these variables. The principal results of the present study showed that there were significant relationships between PA levels and HLSB (E, N, HR, IS, SM and N) in primary education and pre-service teachers. There were significant differences in PA levels, HLSB (E and HR) and dietary habits (calcium intake) between primary education and pre-service teachers.

Despite there being significant differences in age between primary education teachers $(43.15 \pm 9.21)$ and pre-service teachers $(20.32 \pm 1.05)$, we did not find any significant differences in BMI, body weight and body height. This could be explained by the fact that primary education teachers give importance to their body composition and avoid weight gain, in agreement with their high HLSB score. We found that female primary education teachers and pre-service teachers are of normal weight, whereas male primary education and pre-service teachers are overweight according to normative data (Table 1).

Living longer and having a better quality of life are just two of the benefits associated with following a healthy lifestyle, having good dietary habits and regularly participating in PA. People should be encouraged to follow a healthy lifestyle, have good dietary habits and to regularly participate in PA to improve their health and create a healthier society in general. Increasing the level of PA and regulating nutrition are important for a healthy life [10]. Within this composition of behaviours, PA is now becoming more prominent. Immobility plays an important role in disability and increases the risk of mortality. Regular physical exercise prevents or at least delays some chronic diseases $[1,11]$. To create a healthy society, individuals should make efforts to safeguard their health. For this reason, it is fundamental to determine the frequency, duration, intensity and type of PA required for a healthy lifestyle [12]. In line with results of other studies measuring PA levels [10, 13], this study showed that the primary education and pre-service teachers were not active physically. Since PA is crucial for people's health, individuals who are not physically active should be encouraged to take part in PA, and those who have insufficient PA levels should be persuaded to increase their PA. Previous studies have shown that obesity in childhood, adolescence, and young adults is often associated with the future development of adult obesity [14]. Because of this reason, it is imperative that teachers, who are expected to be role models for their students and society, should have good PA habits [10]. Analysis of the PA levels of the primary education and pre-service teachers participating in this study showed that periods of intense PA and total PA were longer for males, while walking and medium level physical activities were longer for females. Female teachers found it sufficient to take a walk and did not engage in any other planned physical activities (Table 2). The PA level and exercise subscale behaviour score of HLSB of the pre-service teachers were significantly higher than of the primary education teachers (Table 2 and Table 3). This result can likely be explained by the age difference. PA levels decrease as age increases despite the well-recognised links between PA and health-related, psychological, cognitive, and social benefits [15]. It is of key importance to manage the decrease in activity at an early stage, before low levels of PA become a habit, and when young adults establish what could be life-long patterns of inactivity [16].

In this study, the mean HLSB scores of the primary education and pre-service teachers were found to be at medium levels according to normative data. The HLSB scores in our study are similar to a previous study carried out in Turkey [17]. While the HLSB scores of the primary education and pre-service teachers were higher for SA, the means of IS, N, E, HR and SM were at medium levels (Table 3). We propose that during their undergraduate study, the efforts of the pre-service teachers to improve their health by implementing a behavioural structure should be supported, and more time should be given to areas where the students received lower scores (E, N, and SM). 
Previous studies have shown that a healthy lifestyle profile including E, N and HR increases with the age of the individual $[18,19]$. However, in the study of Sonmezer et al., no difference between age groups and HLSB was found in Turkish women aged 18-64 [20]. The E, HR and $\mathrm{N}$ subgroup scores of HLSB are significantly higher in the primary education teacher group compared with the pre-service teacher group (Table 3), and this may be explained by the age difference between the two groups (Table 1). The mean scores for HR and N were found to be low, according to normative data suggesting that the participants in our study placed less importance on health issues and nutrition. In our study, the E subgroup score of HLSB was lower for pre-service teachers, who regularly do PA, than for primary education teachers who participate less often in PA. The higher E subgroup score of HLSB for primary education teachers may be because although they place more value on the importance of exercise for health, they do not, for whatever reason, partake regularly in PA.

Some studies have shown that there is a relationship between HLSB and BMI [21-23]; however, we did not find any relationship between BMI and components of HLSB similar to Esatbeyoğlu and Isler [24]. Previous studies have also shown that there is a relationship between cognitive beliefs about leading a healthy lifestyle, including attitudes and intended choices, and PA as well as nutritional rewards [25]. Similarly to previous studies, we found a positive weak $(r=0.201 \mathrm{p}<0.05)$ relationship between PA levels and the exercise subscale behaviour score of HLSB (Table 4).

No significant differences were found in the SM scores between the primary education and pre-service teachers in our study. No correlation between SM and PA level was found; however, there was a correlation $(r=0.539, \mathrm{p}<0.01)$ between the E subgroup score of HLSB and SM (Table 4). Associations between PA and SM have been documented among adults in previous studies, and PA is often proposed as an approach to manage stress [26, 27]. The development of an individual's health is a process wherein the individual is helped to improve their physical and mental health to an optimum level and to make conscious decisions so that they can better their physical and social environments [28].

Evidence suggests that there are possible synergistic effects of multiple lifestyle behaviours on health risks such as obesity and other health outcomes. Therefore, it is prudent to investigate associations between dietary habits and PA behaviours. PA, HLSB and dietary habits may have a significant effect on health [21]. In line with this information, we hypothesized that there is a significant relationship between PA levels, HLSB and dietary habits. While we found a significant relationship between HLSB and some components of energy intake, there was no significant relationship between levels of PA (VIA, MIA and walking) and energy intake components. Consistent with our study, the HELENA study found that the energy intake did not differ significantly between the three PA levels (Table 5).

In our study, protein, pulp, and fibre intake were among mean values according to the Turkish nutrition guide [29], and vitamin A, vitamin D, vitamin K, calcium, ferritin, zinc, magnesium, and vitamin $\mathrm{C}$ were at low levels, while vitamin $\mathrm{E}$, phosphorus, vitamin $\mathrm{B}$, and polyunsaturated fatty acids were at high levels. There is a significant difference in calcium intake level between primary education and pre-service teachers: primary education teachers consume significantly higher calcium compared to pre-service teachers. This result can be explained by the observation that the N subscale of HLSB is higher in primary education teachers suggesting that they might be more aware about the effects of a reduced calcium intake (Table 6).

\section{CONCLUSIONS}

In our study, significant relationships were found between PA levels, HLSB scores and dietary habits in primary education and pre-service teachers, suggesting that HLSB are indicators 
of PA levels and energy intake/dietary habits of primary education and pre-service teachers. We also found that the primary education and pre-service teachers' participation levels in PA were low, their HLSB scores were at low levels according to normative data and their dietary habits were inadequate. These findings suggest that these individuals might be more susceptible to occupational diseases and other diseases. There is a need for education on healthy eating to correct the nutrition imbalance in the primary education teachers and pre-service teachers. Exercise and PA should be increased, and plans should be made for their application and follow-up. In this way, individuals will begin to consciously increase their level of PA, become healthier, and their quality of life will improve. If regular PA during their student years becomes a habit, it will help them to lead a healthy life in the future. The students' knowledge and application of the aspects of a healthy lifestyle and PA will give them an advantage in their quality of life.

Primary education teachers shape the futures of children. In terms of the development of society, teachers are expected to be role models for students and society, so they should be encouraged to follow a healthy lifestyle. Measures that consider the factors obstructing healthy dietary habits should be developed, as it is important for society that higher education students have healthy dietary habits, both for their health and because they should be ideal role models [30].

\section{ACKNOWLEDGMENTS}

The authors would like to extend their thanks to Dr. Melanie KAYIHAN for editing the language of the manuscript and to the volunteers for their willingness to participate in this study.

\section{REFERENCES}

[1] Pate RR, Pratt M, Blair SN, et al. Physical activity and public health: A recommendation from the Centers for Disease Control and Prevention and the American College of Sports Medicine. JAMA. 1995;273(5):402-7. https://doi.org/10.1001/ jama.1995.03520290054029

[2] Kayihan G. Relationship between daily physical activity level and low back pain in young, female desk-job workers. Int J Occup Med Environ Health. 2014;27(5):863-70. https://doi.org/10.2478/s13382-014-0315-3

[3] Kayıhan G, Ersöz G. Hipertansiyon ve egzersiz [Hypertension and exercise]. Spormetre Beden Eğitimi ve Spor Bilimleri Dergisi. 2009;7(3):93-101. Turkish. https://doi.org/10.1501/Sporm_0000000157

[4] Cimen S. Developing "Health Risk Behaviours Scale” in Adolescents between 15 and 18 Years Old. Istanbul, Turkey; 2003.

[5] Esin M. Evaluation and promotion of health behaviors of industry workers. Istanbul University Health Science Institute an Unpublished PhD Thesis, Istanbul; 1997. Turkish

[6] Bize R, Johnson JA, Plotnikoff RC. Physical activity level and health-related quality of life in the general adult population: A systematic review. Prev. Med. 2007;45(6):401-15. https://doi.org/10.1016/j.ypmed.2007.07.017

[7] Bozkuş T, Türkmen M, Kul M, Özkan A, Öz Ü, Cengiz C. Determination and relationships of physical activity level and healthy lifestyle behaviors in physical education students. Int J Sci Culture Sport (IntJSCS). 2013;1(3):49-65.

[8] Walker SN, Sechrist KR, Pender NJ. The health-promoting lifestyle profile: development and psychometric characteristics. Nurs. Res. 1987. https://doi.org/10.1037/t40388-000

[9] Saglam M, Arikan H, Savci S, et al. International physical activity questionnaire: reliability and validity of the Turkish version. Percept Mot Skills. 2010;111(1):278-84. https://doi.org/10.2466/06.08.PMS.111.4.278-284

[10] Sanli E, Guzel NA. Relationship between physical activity level, age, gender and body mass index in teachers. Gazi Beden Eğitimi ve Spor Bilimleri Dergisi. 2009;14(3):23-32.

[11] Pitta F, Troosters T, Probst V, Spruit M, Decramer M, Gosselink R. Quantifying physical activity in daily life with questionnaires and motion sensors in COPD. Eur. Respir. J. 2006;27(5):1040-55. https://doi.org/10.1183/09031936.06.00064105

[12] Montoye HJ. Introduction: evaluation of some measurements of physical activity and energy expenditure. Med Sci Sports Exerc. 2000;32(9):S439-S41. https://doi.org/10.1097/00005768-200009001-00001

[13] Savcı S, Öztürk M, Arıkan H, İnal İnce D, Tokgözoğlu L. Physical activity levels of university students. Archives of the Turkish Society of Cardiology. 2006;34(3):166-72.

[14] Going SB, Lohman TG, Falls HB. Body composition assessment. Fitnessgram/Activitygram Reference Guide (Gregory J. Welk. and Marilu D. Meredith eds.), Dallas, TX: The Cooper Institute. 2008.

[15] Lineweaver TT, Kugler J, Rabellino A, Stephan Y. Beliefs about age-related changes in physical functioning across the adult life span and their relationship with physical activity levels of older adults. Aging Neuropsychol Cogn. 2018;25(4):613-31. https://doi.org/10.1080/13825585.2017.1356903

[16] Leslie E, Fotheringham MJ, Owen N, Bauman A. Age-related differences in physical activity levels of young adults. Med Sci Sport Exerc. 2001;33(2):255-8. https://doi.org/10.1097/00005768-200102000-00014 
[17] Karadeniz G, Uçum EY, Dedeli Ö, Karaağaç Ö. Healthy Lifestyle Behaviors of University Students TAF Prev Med Bull, 2008;7(6):497-502.

[18] Ross CE, Wu C-L. Education, age, and the cumulative advantage in health. J Health Soc Behav. 1996:104-20. https://doi. org/10.2307/2137234

[19] Daskalopoulou C, Koukounari A, Wu Y-T, et al. Healthy ageing trajectories and lifestyle behaviour: the Mexican Health and Aging Study. Sci Rep. 2019;9(1):1-10. https://doi.org/10.1038/s41598-019-47238-w

[20] Sonmezer H, Cetinkaya F, Nacar M. Healthy life-style promoting behaviour in Turkish women aged 18-64. Asian Pac J Cancer Prev. 2012;13(4):1241-5. https://doi.org/10.7314/APJCP.2012.13.4.1241

[21] Ottevaere C, Huybrechts I, Béghin L, et al. Relationship between self-reported dietary intake and physical activity levels among adolescents: The HELENA study. Int J Behav Nutr Phys Act. 2011;8(1):8. https://doi.org/10.1186/1479-5868-8-8

[22] Wang YC, Gortmaker SL, Sobol AM, Kuntz KM. Estimating the energy gap among US children: a counterfactual approach. Pediatrics. 2006;118(6):e1721-e33. https://doi.org/10.1542/peds.2006-0682

[23] Lakerveld J, Rebah MB, Mackenbach JD, et al. Obesity-related behaviours and BMI in five urban regions across Europe: sampling design and results from the SPOTLIGHT cross-sectional survey. BMJ Open. 2015;5(10). https://doi.org/10.1136/ bmjopen-2015-008505

[24] Esatbeyoglu F, Kin Isler A. Physical Activity Levels, BMI and Healthy Life Style Behaviors in Adolescents Living in a Rural District. Turkiye Klinikleri Spor Bilimleri. 2018;10(1). https://doi.org/10.5336/sportsci.2017-57533

[25] Kelly SA, Melnyk BM, Jacobson DL, O'Haver JA. Correlates among healthy lifestyle cognitive beliefs, healthy lifestyle choices, social support, and healthy behaviors in adolescents: implications for behavioral change strategies and future research. J Pediatr Health Care. 2011;25(4):216-23. https://doi.org/10.1016/j.pedhc.2010.03.002

[26] Nguyen-Michel ST, Unger JB, Hamilton J, Spruijt-Metz D. Associations between physical activity and perceived stress/hassles in college students. Stress Health. 2006;22(3):179-88. https://doi.org/10.1002/smi.1094

[27] Paluska SA, Schwenk TL. Physical activity and mental health. Sport Med. 2000;29(3):167-80. https://doi.org/10.2165/00007256 200029030-00003

[28] Yalcinkaya M, Fadime Gok O, Ayla Yavuz K. Evaluation of healthy lifestyle behaviors in health care workers. TAF Preventive Medicine Bulletin. 2007;6.

[29] Turkey Mo. Turkey Dietary Guidelines Ankara: Ministry of Turkey Health Publication; 2016.

[30] Vancelik S, Önal S, Güraksın A, Beyhun E. Related factors with nutritional habits and nutrition knowledge of university students. Türk Sİlahlı Kuvvetlerİ, Koruyucu Hekİmli̇k Bültenİ. 2007;6(4):242-8. 